\begin{tabular}{c} 
Volume and Issues Obtainable at Center for Sustainability Research and Consultancy \\
Journal of Business and Social Review in Emerging Economies \\
ISSN: 2519-089X (E): 2519-0326 \\
Volume 7: Issue 3 September 2021 \\
JSRᄃ \\
Journal homepage: www.publishing.globalcsrc.org/jbsee \\
\hline
\end{tabular}

\title{
A Study of Rural Females of Faisalabad with Reference to their Knowledge and Practices about Personal Hygiene
}

*Paris Zakaullah, Department of Sociology, Government College University, Faisalabad, Pakistan Zahira Batool, Department of Sociology, Government College University, Faisalabad, Pakistan Nazia Malik, Department of Sociology, Government College University, Faisalabad, Pakistan

*Corresponding author's email address: Paris.zaka@gmail.com

\begin{tabular}{l}
\hline ARTICLEDETAILS \\
\hline History \\
Revised format: Aug2021 \\
Available Online: Sep2021 \\
\\
\hline Keywords \\
Knowledge, Practice, \\
Personal Hygiene, Rural \\
Women \\
\hline
\end{tabular}

JEL Classification

Z0O, Z1

\begin{abstract}
Purpose: This study was designed to understand knowledge level and practice of personal hygiene of rural women.

Methodology: This study was conducted in District Faisalabad. Multistage random sampling was used to select the sample. At initial stage of sampling, two towns (Samundari Town and Tandlianwala Town) were selected randomly out of eight towns of District, Faisalabad. Later on, two union councils from each town were finalized and 2 villages were selected from each (four) union councils. Total eight villages were selected for collecting final sample for study. Sample of four hundred respondents was selected from 8 villages by using Solvin formula. At final stage, convenient sampling technique was used to select the respondents from eight villages of District, Faisalabad. A well-established interview schedule was used to collect data from respondents. Data analysis was done by using SPSS. 25 and descriptive statistical techniques were applied to describe summaries of visible characteristics of the dataset.

Findings: It was found that majority of rural women have not enough knowledge about personal hygiene and its practice was missed out due to lack of sufficient knowledge.

Implications: Keeping in view the importance of personal hygiene practices, it is necessary to take measures to improve the situation. Hygiene and sanitation education at the individual or household level needs to be clear and simple.
\end{abstract}

(C) 2021 The authors, under a Creative Commons AttributionNonCommercial 4.0

Recommended citation: Zakaullah, P., Batool, Z. \& Malik, N. (2021). A Study of Rural Females of Faisalabad with Reference to their Knowledge and Practices about Personal Hygiene. Journal of Business and Social Review in Emerging Economies, 7 (3), 659-671.

\section{Introduction \\ Hygiene}

Hygiene is a condition or practice conducive to the maintenance of health and disease prevention, particularly through cleanliness (Kumwenda, 2019). Hygiene is the practice of keeping oneself and one's surroundings clean, in order to prevent disease or the spread of preventable diseases. This is also referred 
to as the activity and actions taken to break the chain of infection transmission at home as well as in the community. Although the lack of clean water, sanitation and prevalence of poor hygiene behavior is a major cause of death among children in developing countries, the polluted environment and poor hygiene practices account for more than 60 percent of the overall burden of diseases among children or adults in these countries (Kimani, Sharif, \& Bashir, 2012).

\section{Hygienic Practice and Knowledge}

Hygiene practices are those activities which are related to cleanliness, such as teeth brushing, clean figures, cutting nails, bathing regularly, washing hands regularly and particularly before handling food, washing scalp hair, maintaining short hair or shaving, wearing clean clothes. On the other hand, hygienic activities focus at disease prevention by using cleanliness as one of the multiple parameters(Asyago, 2005).It is important to recognize that, apart from the family, schools are valuable and stimulating learning environments for children and have the ability to dramatically alter the behavioral patterns of students contributing to better hygiene practices (UNICEF, 2007).

Awareness needs to be given to the community, that public toilets are scarcely available in public areas. Most of the toilets in schools are dysfunctional. Healthcare workers are exposed to low pay and their rights are usually trampled in society. These are some of the key social issues that need to be addressed in order to deliver sanitation services effectively (Khan et al., 2016).

\section{Cultural Hygiene Practices in Pakistan and Developing Countries}

Pakistan ranks among the top ten countries with the most people living without access to safe water. Most urban and rural water comes from groundwater, with more than 50 percent of village households having access to drinking water by hand. According to World Bank reports, 21 per cent of rural people practice open defecation. Ending the open defecation does not mean providing facilities but also changing the behavior of the community towards hygiene practices (Rahman et al., 2018).

There are cultural or religious beliefs in developing countries which govern attitudes towards hygiene. In identifying hygiene authority figure, it must be recognized that in some countries the family traditions are strong and that the mother (women) continues to play a central role in caring for the home and rearing children. On the one hand, this is an advantage in that the transfer of home care education (including hygiene education) to children is a strong tradition in these communities, but there is also a disadvantage in that "outdated / bad" practice as well as good practice can be reinforced. Where the mother is the absolute authority figure, this presents difficulties in achieving a change from "bad" to "good" practice (Marko, 2006).

Due to cultural and historical reasons women are often the primary collectors, transporters and users of water in developing countries. They tend to have primary responsibility for health, child care and are domestic water managers as well as home and community-based sanitation promoters. This division of labour usually results in separate water preferences for women and men. Women's active involvement in water and sanitation solutions can also improve health, improve hygiene practices and status, increase women's protection, build opportunities for income generation, and provide them with other public and influential positions. Women play a central role in supplying, managing, and protecting water. Women and girls probably spend more time gaining water than men and boys. The lack of access to water often reduces women's hygiene habits, contributions in agricultural development, food security and business opportunities (Ahmed, et al., 2017).

\section{Female Knowledge and Practice}

Female participation in hygiene promotion activities is important because of their significant role in household activities in developing countries. Women (mothers \& housewives) are the most suitable target group for improving habits in bathing / washing clothes or utensils, collecting water and selecting water sources, educating children on personal hygiene, washing and disposing of their feces, proper storage of 
water, disposal of human excreta and waste, reduction of accumulation of water in the household and in the general environment (Fisher \& Research, 2006).

Good hygiene practices help women to remain healthy. Keeping themselves safe is really important for women, but they disregard it without knowing that it will have a detrimental impact on their health. Women are the backbone of the home, and their personal hygiene is very important. They do a lot of jobs inside or outside the home. All these aspects of women's life highlight the value of female hygiene (Goldman, Pebley, Beckett, \& medicine, 2001).

Women have limited knowledge of personal hygiene in rural areas. Personal hygiene habits have been influenced by various factors such as inequalities in access to water, sanitation and hygiene facilities, water control, sanitation and hygiene decisions and autonomy, lack of education (hygiene education), cultural norms, parental influence, personal interests, economic status, etc.

\section{Objectives of Study}

Following objectives have been formulated for this study.

$>$ To know the demographic characteristics of the respondents.

$>$ To assess the knowledge and practices on personal hygiene.

$>$ To suggest some valuable measures to solve the issue.

\section{Literature Reviewed}

\section{Personal Hygiene knowledge and Practices}

Angus et al., (2005) concluded thatpersonal hygiene is a concept commonly used in medical practises and in public health. It involves to keep our body and clothing clean. It's defined as a condition for selfpromoting sanitary practises. Personal hygiene knowledge and practise are vital in all of our everyday activities.Personal hygiene's public health purposes include the prevention of faeco-orally transmitted diseases, aesthetic values and social impact.

Biesma et al., (2009)observed that hygiene is the practice of keeping oneself and ones surroundings clean to prevent disease or the spread of diseases that can be prevented. The practice may include hand washing with soap, proper use of sanitation facilities, proper management of human waste disposal and menstrual hygiene. The Global Hand Washing Day has been stepping up the demand for better hygiene standards worldwide since its inception in 2008.

Cleland (2006) noted that personal hygiene components include body hygiene (skin care), oral hygiene (oral care), hand washing (hand care), face hygiene, fingernail and toe nail hygiene (nail care), ear hygiene, hair hygiene, foot hygiene, arm and leg hygiene, clothing hygiene and menstrual hygiene. Several studies indicate that personal hygiene habits include: daily body washing, frequent hand washing, teeth brushing and flossing, simple manicure and pedicure, feminine hygiene, and healthy eating.

Vivas et al., (2010) indicated that In developed countries personal hygiene is very poor. Positive outcomes in personal hygiene are prerequisites for ensuring a stable community. Regardless of religion, ethnicity or place of origin, personal hygiene is a central component of human well-being. However, human health-related behavior results from the impact of various environmental, educational and cultural influences.

Pruss-Ustun and Organization (2008) studied thatgood hygiene practises, safe sanitation and drinking water could prevent about 2.4 million deaths annually. Evidence has shown that hand washing can minimize diarrheal disease incidence by 14-40 percent.

Shridevi et al., (2015) concluded that insufficient knowledge and poor personal hygiene practises lead to various diseases such as halitosis, tonsillitis, infection of the throat, viral hepatitis such as hepatitis A \& E, 
cholera , typhoid, diarrheal and food poisoning, cold, influenza, sinusitis and LRTI, discharge of the ear, boils, dental carriages, periodontal diseases, dandruff, infestation of the lice, scabies, ring worm, fungal infections, boils and many others.

Onsomu (2004) analyzed that the situation in Kenya is equally pathetic even though the Ministry of Education ( MOE) has recommended an average water point standard for every 50 students. An assessment conducted by the Schools Sanitation and Hygiene Working Group in public schools in Machakos, Nairobi and Kiambu found that $90 \%$ of schools in rural Kenya do not have a water source and lack even the simplest washing hand. Out of the 10 per cent of schools where water was available, after visiting the toilet, only a few students washed hands. The study found out in one of the schools where safe running water was available, that after visiting the toilet, only about 20 out of 400 students were washing hands.

Dasgupta and Sarkar (2008) analyzed that It is forbidden for certain societies to talk about menstruation, and the related issues of menstrual sanitation and performance are influenced by multiple factors, however; menstrual knowledge plays a key role in achieving proper hygiene.

According to A. Khan (2000), eating foods considered too hot (dry fruits, liver, and eggs) or too cold (ice creams, yoghurt, and green leafy vegetables) should be avoided by adolescents and their mothers. A possible explanation for this difference is the negligible or poor existence in Pakistani society of food tabous. Other than what is prohibited by religion, food is considered a source of vitality and is the reason for the adolescent girls' regular eating habits during their menstrual period.

Sommers, Mumtaz and Bhatti (2016) stated that needs of MHM in Baluchistan and Punjab, piloting the provision of menstrual hygiene kits to 18,900 young women, and convening a forum with UN-HABITAT and partners to advocate their inclusion in education planning.

L. Scott, Dopson, Montgomery, Dolan and Ryus (2009) reported that girls dispose their used sanitary towels against their teacher's caution and when Maria (2010) conducted a study in the Libode District of Zimbabwe, she observed that most school girls dumped or threw sanitary towels into the pit latrines. In a descriptive cross-cultural study conducted among 190 adolescent girls of a certain rural school in West Bengal, the majority of girls reported being absent from school during their menstrual period giving the excuse that they could not use the sanitary towel disposal bins in their schools because they produced a foul smell. Similar observations among girls in Ghana reported by Scott (2009).

In addition, children can be asymptomatic carriers of pathogens, hampering exclusion.(Gardner \& Hill, 2001)The American Academy of Pediatrics (2011) recommended that child care staff perform recommended hand-hygiene practices throughout the day in conjunction with the following activities: (1) upon arrival for the day, after breaks or when moving from one child care group to another; (2) before and after (a) preparing food or beverages, (b) eating, handling food or feeding a child, (c) Giving or applying a medical ointment or cream in which a break in the skin (sores, cuts or scrapes) may occur; (d) playing in water (including swimming) used by more than one person; and (e) diapering; (3) after (a) using the toilet or helping the child use the toilet; (b) handling body fluid (mucus, blood, vomit) from sneezing, wiping and blowing nose, Or from sores, (c) handling or cleaning of animal waste, (d) playing in sand, on sets of wooden play, and (e) cleaning or handling of garbage. The CDC recommends that the best way to decontaminate the hands is to wash them under warm water for 10-15 seconds.

\section{Materials and Methods}

Present study was conducted to know the knowledge and practice among rural women in Punjab. Universe of the study was villages of District Faisalabad, Punjab. Eight villages were approached through convenient sampling as a target area, and women who were living at the time of study were the population for current investigation. Multistage random sampling was used to select the sample. At initial stage of 
sampling, two towns (Samundari and Tandlianwala) were selected randomly out of eight towns of District, Faisalabad. Later on, two union councils from each town were finalized and each union council assumed 2 villages from four union councils. Total eight villages were selected for collecting final sample for study. Sample of four hundred respondents was selected from 8 villages by using Solving formula. At final stage, convenient sampling technique was used to select the respondents from eight villages of District, Faisalabad. A well-established interview schedule was used to collect data from respondents. Data analysis was done by using SPSS. 25 and descriptive statistical techniques was applied to describe summaries of visible characteristics of the dataset.

\section{Results and Discussion}

\section{Socio-demographic Characteristics of Respondents}

Table 1:Distribution of the respondents according to the age

\begin{tabular}{|l|c|c|}
\hline $\begin{array}{l}\text { Age clusters of the respondents } \\
\text { (in years) }\end{array}$ & $F$ & $\%$ \\
\hline $18-27$ & 76 & 19.0 \\
\hline $28-37$ & 224 & 56.0 \\
\hline $38-47$ & 67 & 16.8 \\
\hline $48-$ Above & 33 & 8.2 \\
\hline Total & 400 & 100.0 \\
\hline
\end{tabular}

According to (Bryant et al., 2016), Age is classified as the total number of years the respondents have completed from the time of birth until the interview. Age is the essential personality variables that make a major contribution to attitudinal development. The assumption that as the age level rises the people's attitude toward any social process changes.

Table 1 depicted age related information of respondents. It revealed that majority $56 \%$ of respondents belong to age category (28-37) and 19\% of the respondents were aged between 18 and 27. Another 16.8\% of respondents were aged between 38 and 47 while $8.2 \%$ of respondents were above 48 . In current study researcher observed the relationship between age, knowledge and practices of personal hygiene. The participants involved in this research were measured in relation to their socio-demographic variables for their practices relating to personal hygiene. Similar results have been found in the Kolkata research conducted by (Mukherjee et al., 2017), the study revealed that the standard of personal hygiene among young girls was better than in older women.

Table 2: Educational level of the respondents

\begin{tabular}{|l|c|c|}
\hline Education level & $F$ & $\%$ \\
\hline Illiterate & 74 & 18.5 \\
\hline Up to 8 & 122 & 30.5 \\
\hline $9-12$ & 117 & 29.2 \\
\hline 13 - above & 87 & 21.8 \\
\hline Total & 400 & 100.0 \\
\hline
\end{tabular}

Education is the systematic transmission of the abilities, knowledge, and meaning of culture from one generation to the next (Magill, 2014). It is regarded as one of the main factors for variation in attitude and reputation of expertise. Mother education makes a strong impact on family environment.In the present study, education has been recognized as the total number of years of schooling completed by the respondents in educational institution. Education of respondents was taken as one of the indicators of 
socio-economic factors which can influence the personal hygiene knowledge and practices of respondents.

Findings from table 2 showed that a majority $30.5 \%$ of respondents were educated up to 8 years followed by $29.2 \%$ of respondents with education between 9 and 12. Further, $21.8 \%$ of respondents possess education of intermediate and above while $18.5 \%$ of respondents were illiterate. The findings of this study were similar to an earlier study conducted by (Barrett \& Browne, 1996), which showed that 138 (55.2 percent) of the 250 mothers had up to 10 years of schooling. They were found to have substantial association with mothers scores of personal hygiene practices and educational level.

Table 3: Marital status of the respondents

\begin{tabular}{|l|c|c|}
\hline Marital status & $F$ & $\%$ \\
\hline Married & 300 & 75.0 \\
\hline Unmarried & 69 & 17.3 \\
\hline Divorced & 14 & 3.5 \\
\hline Widowed & 17 & 4.3 \\
\hline Total & 400 & 100.0 \\
\hline
\end{tabular}

The marital status is each individual's civil status in relation to the country's marriage laws or customs, i.e. single, married, widowed and divorced. It is evident from the findings of table 3 that a great majority of $75 \%$ respondents were married, $17.3 \%$ were unmarried, $4.3 \%$ were widowed and $3.5 \%$ of respondents were divorced.

Table 4: Household's monthly earnings

\begin{tabular}{|l|c|c|}
\hline Household income (PKR) & $F$ & $\%$ \\
\hline $15000-24000$ & 81 & 20.3 \\
\hline $25000-34000$ & 157 & 39.3 \\
\hline $35000-44000$ & 84 & 21.0 \\
\hline Above 44000 & 78 & 19.5 \\
\hline Total & 400 & 100.0 \\
\hline
\end{tabular}

Monthly Income can be defined as total earning of all the family members from all sources within a month.In the 2019-20 budget, the federal government have raised the minimum wage for unskilled workers from Rs 15,000 to Rs 17,500. (Maul, 2012) a month. Minimum wages, as defined by the International Labour Organization are, "The minimum amount of remuneration that an employer is required to pay wage earners for the work performed during a given period." This information indicated that in Pakistan minimum wages started from 15000. Therefor in the present research, monthly income started with in the standard range of wages and it has been divided into given categories which were given above. Findings from table 4 indicated that majority $39.3 \%$ of respondents had a household income between 25,000 and 34,000 followed by $21 \%$ of respondents with income between 35,000 and 44,000. Another $20.3 \%$ of respondents possessed household income between 15,000 and 24,000 while 19.5\% of respondents possessed household income above 44,000. The family's economic well-being was also associated with the general well-being and quality of life. On the other hand, financial strains put a burden on the dynamics of the household or family and influence on the family members' daily life and wellbeing. According to (Hennegan \& Montgomery, 2016), low household income was a major factor in bad hygiene practices. They also suggested that low social and economic levels are a primary cause of poor hygiene practices in people. They advocated procedures to improve awareness and practices about hygiene by manipulating the socioeconomic status, but not only by improving education, but also by 
reallocating income.

\section{Assess the Knowledge and Practices on Personal Hygiene Respondent's Knowledge about Personal Hygiene}

$n=400$

Scale: 1 = Not at all, 2 = To some extent, 3 = To great extent

\begin{tabular}{|l|c|c|c|c|c|c|c|c|}
\hline \multirow{2}{*}{ Statements } & \multicolumn{2}{|c|}{ Not at all } & \multicolumn{2}{c|}{$\begin{array}{c}\text { To some } \\
\text { extent }\end{array}$} & \multicolumn{2}{c|}{$\begin{array}{c}\text { To great } \\
\text { extent }\end{array}$} & Mean & S.D. \\
\cline { 2 - 9 } & $F$ & $\%$ & $F$ & $\%$ & $F$ & $\%$ & \\
\hline $\begin{array}{l}\text { Do you know what personal hygiene } \\
\text { is? }\end{array}$ & 169 & 42.3 & 138 & 34.5 & 93 & 23.3 & 1.81 & .788 \\
\hline $\begin{array}{l}\text { Have you ever heard of the term } \\
\text { "Personal Hygiene' }\end{array}$ & 204 & 51.0 & 132 & 33.0 & 64 & 16.0 & 1.65 & .741 \\
\hline $\begin{array}{l}\text { Do you think personal hygiene is } \\
\text { important? }\end{array}$ & 160 & 40.0 & 135 & 33.8 & 105 & 26.3 & 1.86 & .803 \\
\hline $\begin{array}{l}\text { Do you get the knowledge about } \\
\text { personal hygiene from parents? }\end{array}$ & 175 & 43.8 & 135 & 33.8 & 90 & 22.5 & 1.79 & .787 \\
\hline $\begin{array}{l}\text { If no, do you get the knowledge } \\
\text { about personal hygiene from } \\
\text { teachers or any other source } \\
\text { (media)? }\end{array}$ & 256 & 64.0 & 136 & 34.0 & 8 & 2.0 & 1.38 & .526 \\
\hline $\begin{array}{l}\text { Do you think personal hygiene } \\
\text { means the cleaning concept and any } \\
\text { activities aimed at preserving health } \\
\text { and preventing disease spread? }\end{array}$ & 173 & 43.3 & 137 & 34.3 & 90 & 22.5 & 1.79 & .785 \\
\hline $\begin{array}{l}\text { What does personal hygiene } \\
\text { include? }\end{array}$ & & & & & & & & \\
\hline $\begin{array}{l}\text { Washing hand regularly especially } \\
\text { before } \\
\text { handling food }\end{array}$ & 148 & 37.0 & 158 & 39.5 & 94 & 23.5 & 1.86 & .767 \\
\hline Showering or bathing regularly & 143 & 35.8 & 163 & 40.8 & 94 & 23.5 & 1.88 & .761 \\
\hline Wearing neat clothing & 144 & 36.0 & 162 & 40.5 & 94 & 23.5 & 1.87 & .762 \\
\hline Brushing teeth & 148 & 37.0 & 159 & 39.8 & 93 & 23.3 & 1.86 & .765 \\
\hline Cutting finger nails & 149 & 37.3 & 160 & 40.0 & 91 & 22.8 & 1.85 & .762 \\
\hline Menstrual hygiene & 135 & 33.8 & 172 & 43.0 & 93 & 23.3 & 1.90 & .749 \\
\hline $\begin{array}{l}\text { Do you think menstruation is a } \\
\text { natural process }\end{array}$ & 173 & 43.3 & 121 & 30.3 & 106 & 26.5 & 1.83 & .819 \\
\hline
\end{tabular}

Table 9 presents knowledge of study respondents regarding personal hygiene.The knowledge score was considered poor at 49.9 percent and below, 50 percent -69.9 percent was considered average while 70 percent and above were considered strong. In this study, it was found that 42.3 percent of the sample population didn't know about personal hygiene while 34.5 percent and 23.3 percent had information at some extent and greater extent respectively. Findings of the current study revealed that $51 \%$ of rural women neither heard of personal hygiene nor they had knowledge about personal hygiene.Findings are further validated by the study conducted at Kampala International University by (Muiru,2018), which reported that more than half of 203 respondents $(51.8 \%)$ had insufficient knowledge of personal hygiene practices, with $169(43.1 \%)$ respondents got an average score of between 50\%-69.9\% and $20(5.1 \%)$ respondents scoring $70 \%$ and above. While this was the case that the respondents' overall mean score of 49.4 percent was a disappointing result indicating low personal hygiene knowledge standard.

Personal hygiene was under-estimated in pakistan. Rural women didn't know the value of personal hygiene practices. The percentages of study respondents who reported the importance of and the preference of personal hygiene were $26.3 \%$ at greater extent, $33.8 \%$ at some extent $40 \%$ not at all respectively. This finding was strengthened by (Kandamany\& Mahaffey, 2008) who showed that most women had poor perception of personal hygiene as being essential. But only (23 percent) study respondents recognized that personal health is influenced by open air defection.Most of the respondents were unaware about personal hygiene but parents were the main sources of knowledge for those who 
knew about personal hygiene followed byteachers. Although majority of respondents were not influenced by teachers or media as with respect to personal hygiene. Except few.It was confirmed by (Ghanimet al., 2016) who found that parents and teachers were the most prominent source of personal hygiene information for participants, $77 \%$ and $46 \%$ respectively. From the researcher point of view, this could be attributed to the fact that the study respondents were women and girls who did not inhabit the internal school accommodation they spent just a few hours at school.Much of their time was spent in contact with their mothers at home from whom they were able to teach personal hygiene behavior. They can even watch TV at home showing videos about personal hygiene.so teachers weren't the first source of personal hygiene knowledge.(Abu-Rashid et al., 2017) conducted a study in the Kingdom of Saudi Arabia in which $82.1 \%$ of respondents indicated that their hygiene sources were their mothers, followed by $33.3 \%$ sisters, $23.1 \%$ teachers and $2.6 \%$ books. The knowledge sources about menstrual hygiene were media followed by teachers. This can be demonstrated as the teenage girls may be shy and afraid to speak to their mothers about menstruation.Even their mothers may have taboos to discuss menstruation with them and most of their mothers may be illiterate and do not have any understanding of menarche physiology.Our findings were also supported by the study undertaken in Egypt (El-Gilany et al., 2005), which claimed that mothers, mass media, peers, and friends were the most popular sources of personal and menstrual hygiene information. Also (Upashe et al,.2015) in Ethiopia found that 43.1 percent of mothers were the main source of personal and menstrual hygiene knowledge, followed by 22.96 percent of teachers. In the present study only $22.5 \%$ respondents were aware about the meaning of personal hygiene.The result was in the same lines as the study conducted by (Temitayo, 2016) in Ile-Ife, Nigeria, which reported that 70 percent of respondents did not have any knowledge about the definition of personal hygiene. It was also similar to the study conducted in Ikeja by (Bastos, 2010), which showed that most respondents (80 per cent) had no answer to the definition of personal hygiene.

However, respondents had modest knowledge of the practices included in personal hygiene in the current study. The majority of respondents found practices such as hand washing, showering, clean clothes, teeth brushing, finger nail clipping and menstrual hygiene to be personal hygiene practices. The percentages of study respondents who reported that washing hands regularly especially beforehandling food includes in personal hygiene were $23.5 \%$ at greater extent, $39,5 \%$ at some extent and $37 \%$ not at all respectively. The percentages of study respondents who considered showering or bathing regularly includes in personal hygiene were $23.5 \%$ at greater extent, $40.8 \%$ at some extent and $35.8 \%$ not at all respectively.Similarly, the percentages of study respondents who considered wearing neat clothinginclude in personal hygiene were $23.5 \%$ at greater extent, $40.5 \%$ at some extent and $36 \%$ not at all respectively. The percentages of study respondents who considered brushing teeth includes in personal hygiene were $23.3 \%$ at greater extent, $39.8 \%$ at some extent and $37 \%$ not at all respectively.The percentages of study respondents who considered cutting finger nails include in personal hygiene were $22.8 \%$ at greater extent, $40 \%$ at some extent and $37.3 \%$ not at all respectively.According to the results, the percentages of study respondents who found menstrual hygiene to be included in personal hygiene were $23.3 \%$ at greater extent, $43 \%$ at some extent and $33.8 \%$ not at all respectively.Majority of respondents did not know that menstruation is a natural process.Findings revealed that most of the respondents lacked the requisite menstrual and menstrual hygiene information and possibly did not consider it part of personal hygiene due to their lack of educationAccording to findings, the percentages of study respondents who considered menstruation as a natural process were $26.5 \%$ at greater extent, $30 \%$ at some extent and $43.5 \%$ not at all respectively.Parallel to our study results, (Ali \& Rizvi, 2010) mentioned that according to respondents from Saudi Arabia and India menstruation is neither a natural process nor a common physical transition. It is called disease-induced. While the presence of normal menstruation is proof of the excellent reproductive health of a female, in many cultures the very menstruation is misconstrued as negative and mislabeled.(Mahon \& Fernandes,2010) It was noted that, with respect to participants' knowledge of menstrual hygiene, the majority of participants lacked knowledge of menarche age and period of regular menstrual hygiene. Findings are further confirmed by numerous studies recorded from South Asia where girls had low knowledge of personal hygiene and therefore did not fully comprehend the physical menstrual process. The study by (Dasgupta \& Sarkar, 2008) showed that 37\% girls had knowledge about 
sanitary pad while $63 \%$ girls had no knowledge about sanitary pads as the girls in this study covered class from VIII and above. (UM, Yusuf, \& Musa, 2010)in his study, aimed to assess the knowledge of personal hygiene incidence of menstrual symptoms and preparation for menarche. The author opined that cultures with the highest degree of social rigidity and male solidarity had the strongest code of menstrual taboos. Social and cultural influences affected the transition to menstruation and the early monarchical experience. The author noted that mothers were the key source of knowledge and received some limited education about menstrual cycle with regular emphasis on menstrual hygienic aspects. The study brought the result that women have little knowledge about personal hygiene and practice for their gentile area. The percentage and frequency of the responses on each question were given in the table

$n=400$

Table 10: $\quad$ Respondent's Practices on Personal Hygiene

Scale: 1 = Not at all, $2=$ To some extent, $3=$ To great extent

\begin{tabular}{|c|c|c|c|c|c|c|c|c|}
\hline \multirow[t]{2}{*}{ Practices } & \multicolumn{2}{|c|}{ Not at all } & \multicolumn{2}{|c|}{$\begin{array}{c}\text { To some } \\
\text { extent }\end{array}$} & \multicolumn{2}{|c|}{$\begin{array}{c}\text { To great } \\
\text { extent }\end{array}$} & \multirow[t]{2}{*}{ Mean } & \multirow[t]{2}{*}{ S.D. } \\
\hline & $F$ & $\%$ & $F$ & $\%$ & $F$ & $\%$ & & \\
\hline Do you wash your hands regularly? & 148 & 37.0 & 161 & 40.3 & 91 & 22.8 & 1.86 & 0.761 \\
\hline $\begin{array}{l}\text { Do you wash your hands frequently } \\
\text { in a day? }\end{array}$ & 250 & 62.5 & 123 & 30.8 & 27 & 6.8 & 1.44 & 0.619 \\
\hline $\begin{array}{l}\text { After washing your hand do you dry } \\
\text { your hands completely }\end{array}$ & 273 & 68.3 & 107 & 26.8 & 20 & 5.0 & 1.37 & 0.577 \\
\hline $\begin{array}{l}\text { Do you wash your hands before } \\
\text { eating? }\end{array}$ & 29 & 7.3 & 239 & 59.8 & 132 & 33.0 & 2.26 & 0.581 \\
\hline $\begin{array}{l}\text { Do you wash your hands after } \\
\text { eating? }\end{array}$ & 206 & 51.5 & 124 & 31.0 & 70 & 17.5 & 1.66 & 0.759 \\
\hline $\begin{array}{l}\text { Do you wash your hands after using } \\
\text { the toilet? }\end{array}$ & 7 & 1.8 & 204 & 51.0 & 189 & 47.3 & 2.45 & 0.533 \\
\hline $\begin{array}{l}\text { Do you wash your hands after } \\
\text { touching animals? }\end{array}$ & 147 & 36.8 & 145 & 36.3 & 108 & 27.0 & 1.90 & 0.793 \\
\hline $\begin{array}{l}\text { Do you wash your hands after } \\
\text { cleaning home? }\end{array}$ & 131 & 32.8 & 149 & 37.3 & 120 & 30.0 & 1.97 & 0.793 \\
\hline $\begin{array}{l}\text { Do you wash your hands after } \\
\text { touching garbage? }\end{array}$ & 52 & 13.0 & 194 & 48.5 & 154 & 38.5 & 2.26 & 0.672 \\
\hline $\begin{array}{l}\text { Do you use soap/hand wash for } \\
\text { hand washing }\end{array}$ & 56 & 14.0 & 202 & 50.5 & 142 & 35.5 & 2.22 & 0.671 \\
\hline $\begin{array}{l}\text { Do you cover the nose and mouth } \\
\text { with a tissue or the hand when } \\
\text { coughing or sneezing? }\end{array}$ & 224 & 56.0 & 136 & 34.0 & 40 & 10.0 & 1.54 & 0.670 \\
\hline $\begin{array}{l}\text { Do you clean the teeth at least once } \\
\text { a day }\end{array}$ & 221 & 55.3 & 106 & 26.5 & 73 & 18.3 & 1.63 & 0.774 \\
\hline $\begin{array}{l}\text { Do you brush the teeth after every } \\
\text { meal }\end{array}$ & 262 & 65.5 & 112 & 28.0 & 26 & 6.5 & 1.41 & 0.611 \\
\hline $\begin{array}{l}\text { Do you use tooth paste while } \\
\text { brushing? }\end{array}$ & 206 & 51.5 & 139 & 34.8 & 55 & 13.8 & 1.62 & 0.715 \\
\hline Do you take bath regularly? & 216 & 54.0 & 94 & 23.5 & 90 & 22.5 & 1.69 & 0.817 \\
\hline $\begin{array}{l}\text { Do you wash the hair with soap or } \\
\text { shampoo at least once a week? }\end{array}$ & 211 & 52.8 & 99 & 24.8 & 90 & 22.5 & 1.70 & 0.814 \\
\hline Do you change your clothes daily? & 233 & 58.3 & 101 & 25.3 & 66 & 16.5 & 1.58 & 0.758 \\
\hline $\begin{array}{l}\text { Do you hanging clothes in the sun to } \\
\text { dry }\end{array}$ & 249 & 62.3 & 117 & 29.3 & 34 & 8.5 & 1.46 & 0.648 \\
\hline Do you use soap when bathing? & 50 & 12.5 & 234 & 58.5 & 116 & 29.0 & 2.17 & 0.623 \\
\hline $\begin{array}{l}\text { Do you use cotton swabs to clean } \\
\text { ear? }\end{array}$ & 239 & 59.8 & 133 & 33.3 & 28 & 7.0 & 1.47 & 0.625 \\
\hline $\begin{array}{l}\text { Do you cut your nails at least once } \\
\text { in a week? }\end{array}$ & 223 & 55.8 & 122 & 30.5 & 55 & 13.8 & 1.58 & 0.721 \\
\hline \multicolumn{9}{|l|}{$\begin{array}{l}\text { What type of absorbent material do } \\
\text { you use during menstruation? }\end{array}$} \\
\hline Sanitary pad & 227 & 56.8 & 65 & 16.3 & 108 & 27.0 & 1.70 & 0.867 \\
\hline Cloth & 54 & 13.5 & 157 & 39.3 & 189 & 47.3 & 2.34 & 0.703 \\
\hline
\end{tabular}




\begin{tabular}{|l|c|c|c|c|c|c|c|c|}
\hline \multicolumn{1}{|c|}{ Panties } & 362 & 90.5 & 19 & 4.8 & 19 & 4.8 & 1.14 & 0.467 \\
\hline \multicolumn{1}{|c|}{ Others } & 282 & 70.5 & 14 & 3.5 & 4 & 1.0 & 1.06 & 0.269 \\
\hline $\begin{array}{l}\text { How many times do you change } \\
\text { pads in a day? }\end{array}$ & & & & & & & & \\
\hline \multicolumn{1}{|c|}{ Once a day } & 97 & 24.3 & 81 & 20.3 & 222 & 55.5 & 2.31 & 0.838 \\
\hline \multicolumn{1}{|c|}{ Thice a day } & 236 & 59.0 & 54 & 13.5 & 110 & 27.5 & 1.69 & 0.876 \\
\hline $\begin{array}{l}\text { Do you use paper for wrapping the } \\
\text { pad when dispose }\end{array}$ & 215 & 75.3 & 32 & 83.0 & 67 & 16.8 & 1.41 & 0.761 \\
\hline $\begin{array}{l}\text { Do you use dustbin for disposing } \\
\text { sanitary towel? }\end{array}$ & 212 & 53.0 & 90 & 22.5 & 98 & 24.5 & 1.72 & 0.834 \\
\hline $\begin{array}{l}\text { Do you wash hands after changing } \\
\text { sanitary napkin? }\end{array}$ & 49 & 12.3 & 220 & 55.0 & 131 & 32.8 & 2.20 & 0.640 \\
\hline $\begin{array}{l}\text { Do you take bath daily during } \\
\text { menstruation }\end{array}$ & 230 & 57.5 & 140 & 35.0 & 30 & 7.5 & 1.50 & 0.633 \\
\hline Do you use soap when bathing? & 132 & 33.0 & 177 & 44.3 & 91 & 22.8 & 1.90 & 0.741 \\
\hline
\end{tabular}

Table 10 indicated respondent's practices on personal hygiene. Findings showed that study population who washed their hands regularly in a day were $22.8 \% \%$ at greater extent, $40.3 \%$ at some extent and $37.0 \%$ not at all respectively. The percentages of study respondents who washed their hands frequently in a day were $6.8 \%$ at greater extent, $30.8 \%$ at some extent and $62.5 \%$ not at all respectively. According to findings, the percentages of study respondents who dry up their hands completely after washing were $5.0 \%$ at greater extent, $26.8 \%$ at some extent and $28.3 \%$ not at all respectively. (Jumaa, 2005)It has been stated that the basic and first step in all hygiene activities is hand washing and hand hygiene is central to preventing the spread of infectious diseases in the home and in daily living environments. According to (Pittet, 2000), Previous research cited the less common practices of hand washing by respondents (27.3 per cent. Reported findings were also similar to a study carried out in Peru (Hartinger et al., 2016), in which mothers typically dried their hands with their dresses or any "reasonably" clean cloth. It is conceivable that this method provides the risk of contamination. Although according to current knowledge studies of the effects of improper hand drying on the incidence of diarrhea, especially in young children, are restricted. In the current study, just before eating, after using toilets and after touching garbage were the major episodes when the women washed their hands and used soap as compared to other activities such as touching the animal or cleaning the house. The percentages of study respondents who wash their hands before eating were $33 \%$ at greater extent, $59.8 \%$ at some extent and $7.3 \%$ not at all respectively. The percentages of study respondents who wash their hands after eating were $17.5 \%$ at greater extent, $31 \%$ at some extent and $51.5 \%$ not at all respectively. According to findings, the percentages of study respondents who wash their hands after using toilet were $47.3 \%$ at greater extent, $51 \%$ at some extent and $1.8 \%$ not at all respectively. The percentages of study respondents who wash their hands after touching animals were $27 \%$ at greater extent, $36.3 \%$ at some extent and $36.8 \%$ not at all respectively. The percentages of study respondents who wash their hands after cleaning home were $30 \%$ at greater extent, $37.3 \%$ at some extent and $32.8 \%$ not at all respectively. According to findings, the percentages of study respondents who wash their hands after touching garbage were $38.5 \%$ at greater extent, $48.5 \%$ at some extent and $13 \%$ not at all respectively.

Similarly, according to a study done by (Karki, Rajbhandari, Dahal, Shahi, \& Sharma, 2018) in Kathmandu, When it comes to hand hygiene practices, the self-reported frequency of hand washing before meals among girls in that study is significantly higher (96.2 percent) than in other studies. , for example, studies from Bangladesh, Philippine and Colombia showed that 91 percent 75.9 percent and 46.9 percent of females reported washing hands before meals. This can be explained by cultural patterns, food types and the use of hands or utensils when eating food. Most of the meals are eaten with hands in Nepal so greater emphasis is put on washing hands before meals. However, after taking meal the practice was bad. It was found that more than $50 \%$ of the respondents did not wash their hands with soap after meal. Washing hands after defecation is one of the most effective ways to prevent gastrointestinal parasitic infections. While $47.3 \%$ of women reported washing hands after defecation at greater extent. 
(Rajbhandari, Dhaubanjar, GC, \& Dahal, 2018) It has been shown that the transfer of microorganisms to the hands was due to inadequate personal hygiene habits after using the toilet, as people do not use soap to wash their hands after using the toilet, washing children and touching waste. They found that the most commonly polluted contact surfaces were the hands compared to any other surfaces of contact. According to this study, the percentages of study respondents who use soap or hand wash for washing their hands were $35.5 \%$ at greater extent, $50.5 \%$ at some extent and $14 \%$ not at all respectively. Overall, the majority of respondents reported using soap for washing hands. The study done by (Jensen, Danyluk, Harris, \& Schaffner, 2015) showed that 53 percent of people used soap for washing hands.

Hence, females, particularly adolescents, have to be prepared psychologically for the physical changes that occur during this time. And before their menarche, they should be well informed of menstruation, menstrual hygiene and menstrual cycle, as well as how to maintain hygiene throughout the period. Lack of knowledge and attitudes about personal and menstrual hygiene are factors that contribute to poor personal hygiene. Practicing hygiene has the greatest benefit of reducing disease transmission and increasing health and social status within the society. The study emphasized there is no substitute for good practices of personal hygiene to lead a safe life. Therefore, regular health education programs should be conducted to educate rural women regarding good personal hygiene practices.

\section{Conclusion}

It was concluded that that most of rural women had no or very little knowledge about the importance of hygiene. Most respondents lacked necessary knowledge about menstruation and menstrual hygiene and did not consider it as party of personal hygiene probably due to their lack of education. Personal hygiene involves an individual's practice of caring for one's physical health and well-being through cleanliness. Personal hygiene includes hand hygiene, oral hygiene, body hygiene and menstrual hygiene, including all forms of personal hygiene. Hygiene practices are those activities which are related to cleanliness, such as teeth brushing, cutting finger nails, bathing regularly, washing hands regularly and particularly before handling food, washing scalp hair, maintaining short hair or shaving, wearing clean clothes. Due to cultural and historical reasons Women are often the primary collectors, transporters and users of water in developing countries. They tend to have primary responsibility for health, child care and are domestic water managers as well as home and community-based sanitation promoters.

Consequently, their personal hygiene practices were also poor.It was observed that socio-demographic factors have a strong influence on personal hygiene practices. There was higher level of knowledge and awareness in those women who were young and those who had better education level and better financial position. there were number of barriers which affected personal hygiene practices. Financial constraints and lack of facilities for hand washing were reported as the main barriers in practicing personal hygiene. Further, gender inequality, cultural constraints, lack of political determination, low parental education, inadequate water supply and poor sanitation were also some of the major barriers in practicing personal hygiene

\section{Suggestions}

- Keeping in view the importance of personal hygiene practices, it is necessary to take measures to improve the situation.

- Hygiene and sanitation education at the individual or household level needs to be clear and simple.

- Systematic attempts to promote awareness among growing children and parents about the importance of personal hygiene, improving parental literacy combined with economic empowerment of rural families will play a crucial role in enhancing our rural women's personal hygiene status and thereby dramatically decreasing their disease burden.

\section{References}


Ahmed, U.I.; Ying, L.; Bashir, M.K.; Abid, M.; Zulfigar, F. Status and determinants of small farming households' food security and role of market access in enhancing food security in rural Pakistan. PLoS ONE 2017, 12, e0185466.

Angus, J., Kontos, P., Dyck, I., McKeever, P., \& Poland, B. (2005). The personal significance of home: habitus and the experience of receiving long-term home care. Sociology of Health \& Illness, 27(2), 161-187. doi:10.1111/j.1467-9566.2005.00438.x

Assefa, M., \& Kumie, A. (2014). Assessment of factors influencing hygiene behaviour among school children in Mereb-Leke District, Northern Ethiopia: a cross-sectional study. BMC public health, 14(1), 1000.

Biesma, R. G., Brugha, R., Harmer, A., Walsh, A., Spicer, N., \& Walt, G. (2009). The effects of global health initiatives on country health systems: a review of the evidence from HIV/AIDS control. Health Policy and Planning, 24(4), 239-252. doi:10.1093/heapol/czp025

Cairncross, S., Bartram, J., Cumming, O., \& Brocklehurst, C. J. P. M. (2010). Hygiene, sanitation, and water: what needs to be done? , 7(11).

Cairncross, S., \& Valdmanis, V. (2006). Water supply, sanitation and hygiene promotion (Chapter 41).

Cleland, J., Conde-Agudelo, A., Peterson, H., Ross, J., \& Tsui, A. (2012) Family Planning 2 Contraception and health. The Lacent, 380(9837), 149-156

Dasgupta, A., \& Sarkar, M. (2008). Menstrual hygiene: how hygienic is the adolescent girl? Indian journal of community medicine: official publication of Indian Association of Preventive \& Social Medicine, 33(2), 77.

Fisher, C. M., \& Buglear, J. (2007). Researching and writing a dissertation: A guidebook for business students: Pearson Education.

Gardner, T. B., \& Hill, D. R. (2001). Treatment of giardiasis. Clinical microbiology reviews, 14(1), 114128.

Goldman, N., Pebley, A. R., Beckett, M. J. S. s., \& medicine. (2001). Diffusion of ideas about personal hygiene and contamination in poor countries: evidence from Guatemala. 52(1), 53-69.

Hartinger, S. M., Lanata, C. F., Hattendorf, J., Gil, A. I., Verastegui, H., Ochoa, T., \& Mäusezahl, D. (2011). A community randomised controlled trial evaluating a home-based environmental intervention package of improved stoves, solar water disinfection and kitchen sinks in rural Peru: Rationale, trial design and baseline findings. Contemporary Clinical Trials, 32(6), 864873. doi:10.1016/j.cct.2011.06.006

Jensen, D. A., Danyluk, M. D., Harris, L. J., \& Schaffner, D. W. (2015). Quantifying the effect of hand wash duration, soap use, ground beef debris, and drying methods on the removal of Enterobacter aerogenes on hands. Journal of Food Protection, 78(4), 685-690.

Jumaa, P. (2005). Hand hygiene: simple and complex. International Journal of Infectious Diseases, 9(1), 3-14.

Karki, S., Rajbhandari, A. K., Dahal, M., Shahi, P., \& Sharma, S. (2018). Knowledge and practice on menstrual hygiene among adolescent girls of selected slums in Kathmandu valley. Journal of Patan Academy of Health Sciences, 5(2), 114-122.

Khan, A. (1999). Mobility of women and access to health and family planning services in Pakistan. Reproductive health matters, 7(14), 39-48.

Khan, A. I., Danish, S. H., Ashfaq, A., Ahmad, F., Warsi, S. M. A., \& Khan, M. P. J. J. o. t. D. U. o. H. S. (2016). Knowledge, Attitude and Practices of Mothers Regarding Diarrheal Risk Factors and Management in under 5 Children: A Cross Sectional Survey in Dadu and Badin Districts of Sindh, Pakistan. 10(1).

Khan, M., \& Manderson, L. (1992). Focus groups in tropical diseases research. Health policy and planning, 7(1), 56-66.

Kimani, F., Sharif, S., \& Bashir, I. J. N., Kenya. (2012). Ministry of Public Health and Sanitation and Ministry of Medical Services National Cervical Cancer Prevention Program in Kenya: Strategic Plan 2012-2015. Nairobi.

Kumwenda, S. (2019). Challenges to hygiene improvement in developing countries The Relevance of Hygiene to Health in Developing Countries: InTechOpen. 
Lahiri, S., \& Chanthaphone, S. (2003). Water, sanitation and hygiene: a situation analysis paper for Lao PDR. International Journal of Environmental Health Research, 13(sup1), S107-S114.

Mahon, T., Fernandes, M. J. G., \& Development. (2010). Menstrual hygiene in South Asia: a neglected issue for WASH (water, sanitation and hygiene) programmes. 18(1), 99-113.

Marko, T. L. (2006). When they became the nation's children: The foundationsof pediatrics and its raced, classed, and gendered (re) inventionsof childhood in Rio de Janeiro, 1870-1930: University of California, San Diego.

Pittet, D., Allegranzi, B., Storr, J. J. J. o. I., \& Health, P. (2008). The WHO Clean Care is Safer Care programme: field-testing to enhance sustainability and spread of hand hygiene improvements. $1(1), 4-10$.

Pruss-Ustun, A., \& Organization, W. H. (2008). Safer water, better health: costs, benefits and sustainability of interventions to protect and promote health.

Rahman, A., Tosepu, R., Karimuna, S. R., Yusran, S., Zainuddin, A., \& Junaid, J. J. P. H. o. I. (2018). Personal Hygiene, Sanitation And Food Safety Knowledge Of Food Workers At The University Canteen In Indonesia. 4(4), 154-161.

Rajbhandari, A. K., Dhaubanjar, R., GC, K. B., \& Dahal, M. (2018). Knowledge and practice of personal hygiene among secondary school students of grade nine and ten. Journal of Patan Academy of Health Sciences, 5(2), 107-113.

Sommer, M. (2012). Menstrual hygiene management in humanitarian emergencies: gaps and recommendations. Waterlines, 83-104.

UNICEF. (2007). The state of the world's children 2008: Child survival (Vol. 8): Unicef.

Vivas, A., Gelaye, B., Aboset, N., Kumie, A., Berhane, Y., \& Williams, M. A. (2010). Knowledge, attitudes, and practices (KAP) of hygiene among school children in Angolela, Ethiopia. Journal of preventive medicine and hygiene, 51(2), 73. 